\title{
Pendidikan Kesehatan Reproduksi Pada Remaja
}

\author{
Dian Permatasari ${ }^{1}$, Emdat Suprayitno ${ }^{2 *}$ \\ ${ }^{1,2}$ Fakultas Ilmu Kesehatan Universitas Wiraraja \\ *Email: emdat@wiraraja.ac.id
}

\begin{abstract}
Background: Reproductive health has the concept that everyone can have a satisfying and safe and responsible sex life. Therefore, it is the right of every teenager to be informed and have acces to true,complete and honest reproductive and sexsual health. The main objective of reproductive health is to provide comprehensive reproductive health services to individuals and their partners, especiallyto adolescents so that each individual is able to purpose is to undergo the reproductive process. Methods: The method used in this community service uses counseling or socialization directly to the target, namely teenagers. Its specific purpose is to protect adolescents from the risk of early marrieage, unwanted pregnancy, abortion, Sexually Transmitted Infection (STIS), HIV/AIDS and sexual violence. Results: The results showed that health counseling on reproductive health for adolescents in Nambakor village, sumenep regency was going well and carried out according to the goals and teenagers were very enthusiastic about participating in the counseling and very benificial for adolescents and the community. Conclusion: Suggestions are expected to be additional information regarding the importance of promotive, preventive, curative efforts in this case the importance of knowledge of productive health.
\end{abstract}

Keywords: HIV/AIDS; reproductive health; teenager

\section{PENDAHULUAN}

Kesejahteraan fisik, psikjologis maupun social yang menyeluruh dan tidak terlepas oleh penyakit yang meliputi segala yang berhubungan dengan fisiologis dan proses reproduksi (Indriyani \& Suprayitno, 2017). Badan kesehatan dunia (WHO) menjelaskan masalah kesehatan reproduksi pada perempuan pada kondisi yang tidak baik sudah mencakup angka 33\% dari keseluruhan beban penyakit yang menderita perempuan di dunia (Permatasari \& Suprayitno, 2020). Sebanyak 55,76\% (29 orang) remaja di Desa Nambakor mereka kurang mendapatkan informasi yang optimal tentang kesehatan reproduksi dan mereka banyak bertanya kepada tenaga kesehatan tetapi informasi yang didapat kurang maksimal. Masa remaja merupakan masa transisi antara masa anak-anak hingga masa dewasa. Remaja pada tahap ini belum belum mencapai kematangan mental dan sosial sehingga remaja harus menghadapi banyak tekanan emosi dan sosial yang saling bertentangan (Permatasari \& Suprayitno, 2021).

Pasa masa puber anak dewasa akan mengalami perubahan fisik yang signifikan seperti kemampuan system reproduksi. Akan Tetapi fakta menunjukkan sebagian besar remaja tidak paham dan pada kondisi kesehatan reproduksi seperti siklus menstruasi dan proses terjadinya kehamilan (Ernawati, 2018). Tingginya perilaku asusila serta pergaulan bebas oleh remaja banyak diakibatkan oleh berbagai faktor. Sebagai penyebab tertinggi adalah kurangnya pengetahuan tentang seks yang benar baik pada kalangan remaja. Pendidikan kesehatan reproduksi pada remaja dapat menjadi salah satu solusi agar para remaja lebih bijak dan berhati-hati dalam menanggapi perilaku seksual berisiko sehingga dapat terhdindar dari berbagai penyakit menular seksual dan dapat menerapkan perilaku yang sehat.

Tujuan pelaksanaan pengabdian ini adalah menambah wawasan dan meyampaikan pentingnya kesehatan reproduksi kepada remaja di Desa Nambakor Kabupaten Sumenep dengan memberikan penyuluhan. 


\section{TINJAUAN PUSTAKA}

Masa remaja,menurut Mappiare berlangsung antara umur 12 tahun sampai dengan 21 tahun bagi wanita dan 13 tahun sampai dengan 22 tahun bagi pria. Remaja yang dalam bahasa aslinya adolescence, berasal dari bahasa latin adolescere yang artinya"tumbuh untuk mencapai kematangan". Perkembangan lebih lanjut, istilah adolescence sesungguhnya memiliki arti yang luas, mencakup kematangan mental ,emosional, sosial, dan fisik(E. Suprayitno et al., 2020). Kesehatan reproduksi merupakan kondisi sehat dan sejahtera secara fisik, psikologis dan sosial yang seluruhnya terbebas dari penyakit atau adanya cacat dalam yang berhubungan dengan sistem reproduksi.

Manfaat dan tujuan dari program kesehatan reproduksi remaja yaitu memberikan pemahaman dan kesadaran agar menyadari pentingnya mempelajari ilmu tersebut yang dapat berdampak pada perilaku hidup sehat dan juga bertanggung jawab kepada masalah kondisi kesehatan reproduksinya setiap hari, cara yang ditempuh dengan melakukan upaya advokasi, promosi kesehatan, KIE, konsultasi dan memberikan pelayanam kepada remaja dengan permasalahan khusus dan memberikan support dalam melaksanakan kegiatan positif yang melibatkan remaja (Arsani,2019). Pendidikan Kesehatan adalah aplikasi atau penerapan pendidikan dalam bidang kesehatan. Secara opersional pendidikan kesehatan adalah semua kegiatan untuk memberikan dan meningkatkan pengetahuan, sikap, praktek baik individu, kelompok atau masyarakat dalam memelihara dan meningkatkan kesehatan mereka sendiri (Suprayitno \& Wahid,2019).

Menurut WHO (1954) pendidikan kesehatanadalah untuk mengubah prilaku orang atau masyarakat dari prilaku tidak sehat menjadi prilaku sehat.seperti kita ketahui bila prilaku tidak sesuai dengan prinsip kesehatan maka dapat menyebabkan terjadinya gangguan terhadap kesehatan (Suprayitno \& Huzaimah, 2020).

\section{DESAIN PENELITIAN}

\section{Tahapan Awal}

Pertama yaitu Sosialisasi pelaksanaan Pendidikan kesehatan ini ditujukan dalam memastikan kesiapan tempat dan sasaran yang ada pada mitra sebagai gambaran awal tempat kegiatan. Dalam pelaksanaan sosialisasi ini kami memberikan penyuluhan tentang keseheatan reproduksi pada remaja di Desa Nambakor diharapkan mereka lebih paham tentang pengetahuan Kesehatan remaja secara jelas. Kedua, Penyusunan Materi pendidikan kesehatan dibuat dalam variasi 2 bentuk yaitu leaflet dan materi dalam bentuk PPT (power point), nantinya dari bentul leflet diberikan kepada remaja tersebut sebelum diberikan penjelasan pengetahuan dalam bentuk power point dimana nantinya ada diskusi tanya jawab.

Ketiga menyiapkan peralatan dan media penyuluhan. Peralatan dan media yang harus disiapkan yaitu kelengkapan dan denah ruang tempat penyuluhan. Untuk peralatan yang disiapkan laptop dan OHP serta media yang digunakan yaitu berupa gambar nantinya yang disajikan dalam PPT. Keempat Pelaksanaan Penyuluhan pada tanggal 18 Februari 2021 Tahapan penyuluhan pada remaja di Desa Nambakor Kecamatan Sumenep dilakukan penyuluhan pengetahuan tentang kesehatan reproduksi pada remaja (KRR) dan diharapkan dapat meningkatkan pengetahuan serta sikap remaja tersebut. Kelima Pelaporan Akhir, Setelah dilakukan penyuluhan dan sosialisasi 
selanjutnya dibuat laporan akhir dimana yang dilaporkan tentang sasarannya dan keberhasilan kegiatan pengabdian kepada masyarakat di Desa Nambakor.

\section{Tahapan Pelaksanaan}

Pertama Koordinasi dengan Kepala Desa Nambakor Kabupaten Sumenep, Pemberian pengarahan dan materi kepada remaja dan keluarga berencana di Desa Nambakor Kabupaten Sumenep dan evaluasi kegiatan. Kedua Tahapan Monitoring dan Evaluasi Metode yang digunakan dalam kegiatan pengabdian ini adalah penyuluhan kesehatan pada remaja menggunakan penyampaian materi dan tanya jawab.

a. Survei Awal

b. Analisis Situasi

c. Koordinasi Tim

d. Penentuan Masalah Mitra

e. Menyusun Rencana Proposal

f. Pelaksaan PKM

g. Penyusun Hasil PKM

h. Pelaporan

\section{HASIL PENELITIAN}

Hasil kegiaan pendidikan kesehatan di balai desa nambekor Kabupaten sumenep diikuti oleh 10 remaja di balai desa nambekor kabupaten sumenep. Dari kegiatan yang telah di lakukan dalam bentuk pendidikan kesehatan tetdapat beberapa hasil evaluasi yaitu evaluasi struktur, Kepala desa perangkat desa dan kader kesehatan dapat bekerja sama dengan baik dan kooperatif di buktikan dengan dalam persiapan kegiatan dan ikut serta menyiapkan atau membuat setting tempat pendidikan kesehatan. Evaluasi proses, Pelaksanaaan pendididkan kesehatan terlihat aktof diikuti remaja di balai Desa Nambakor Kabupaten Sumenep, remaja dan keluarga berencana aktif dalam bertanya tentang kesehatan reproduksi atau kebutuhan yang dibutuhkan pada haid pertama.

Peserta kegiatan dapat mengerti tentang kesehatan reproduksi kebutuhan yang dibutuhkan pada haid pertama serta dapat menjelaskan kembali apa yang telah disampaikan. Evaluasi Hasil, Peserta kegiatan dapat mengerti serta memahami tentang pentingnya menjaga kesehatan reproduksi dan dapat menjaga kesehatan reproduksi.

\section{PEMBAHASAN}

Berdasarkan hasil penyuluhan tentang kesehatan reproduksi remaja terhadap peningkatan pengetahuan serta sikap remaja berdampak baik khususnya remaja dapat meningkatkan pengetahuannya dalam menjaga kesehatan reproduksi. Sosialisasi dengan metode menggunakan health education dengan Teknik menyampaikan pesan, secara langsung gunanya untuk meningkatkan kepercayaan yang berdampak pada kesadaran, kemauan dan pemahaman dalam melaksanakan saran dan anjuran yang berkaitan dengan kesehatan pada system reproduksi (Suprayitno et al., 2018). Keberhasilan penyuluhan yang berfokus pda remaja dipengaruhi oleh bahan ajar yang disampaikan dengan baik dan jelas (Permatasari \& Suprayitno, 2021).

Media pendidikan kesehatan adalah alat yang bantu yang dapat dipakai oleh tenaga pendidik dalam proses penyampaian bahan pelajaran. Dari penelitan para ahli, mata merupakan indera yang paling sering menyampaikan pesan dari materi dalam Pendidikan kesehatan (kurang lebih $75 \%$ sampai 87\%) sedangkan $/ 25 \%$ pengetahuan seseorang didapatkan dari indera lainnya yang berdampak bertambah banyak pancaindra digunakan maka semakin jelas informasi yang didapatkan (Pakpahan et al. 
2021). Media Audio dan media visual adalah media yang bisa menyampaikan informasi dan pesan melalui indera penglihatan dan pendengaran (Katharina \& Yuliana, 2017).

\section{KESIMPULAN DAN SARAN}

Penyuluhan kesehatan tentang kesehatan reproduksi pada remaja di Desa Nambakor Kabupaten Sumenep. Berjala dengan baik dan terlaksana sesuai dengan tujuan dan rencana. Kegiatan ini juga mendapat sembutan yang baik dari kepala desa, kader perangkat desa dan masyarakat setempat diamana semua remaja sangat tertarik menghadiria penyeluhan tersebut dan sangat bermanfaat bagi remaja masyarakat. Kegiatan pemyeluruhan kesehatan tersebut berdampak positif bagi remaja dan masyarakat sehingga dapat mewujudkan peningkatan pengatahuan remaja tentang cara menjaga kesehatan reproduksi.

Di desa nambekor kabupaten sumenep perlu meningkatakan fungsi prongram kesehatan sehingga remaja dan masyarakat mendapatkan pengatahuan yang tepat. Bagi remaja dan masyarakat sebagai media informasi tentang manfaat dari melakukan upaya promotif, preventif dan kuratif yang berhubungan dengan kesehatan reproduksi.

\section{UCAPAN TERIMA KASIH}

Ucapan terimakasih kami berikan kepada individu maupun kelompok yang sudah membantu menyelesaikan PKM ,baik penulis, pembimbing ,dan perangkat desa yang telah membantu.

\section{DAFTAR RUJUKAN}

Arsani, N. L. K. A. (2019). Peranan program PKPR (pelayanan kesehatan peduli remaja) terhadap kesehatan reproduksi remaja di kecamatan Buleleng. Jurnal Ilmu Sosial Dan Humaniora, 2(1).

Ernawati, H. (2018). Pengetahuan kesehatan reproduksi remaja di daerah pedesaan. Indonesian Journal for Health Sciences, 2(1), 58-64.

Indriyani, R., \& Suprayitno, E. (2017). Hubungan Postpartum Blues Dengan Keputusan Menggunakan KB Pasca Nifas Di UPT Puskesmas Lenteng. Journal Of Health Science (Jurnal Ilmu Kesehatan), 2(2), 70-75.

Katharina, T., \& Yuliana, Y. (2017). Pengaruh Penyuluhan Kesehatan Reproduksi melalui Audio Visual dengan Hasil Pengetahuan Setelah Penyuluhan pada Remaja SMA Negeri 2 Pontianak Tahun 2017. Jurnal Kebidanan, 8(1), 265367.

Pakpahan, M., Siregar, D., Susilawaty, A., Tasnim, T., Ramdany, R., Manurung, E. I., Sianturi, E., Tompunu, M. R. G., Sitanggang, Y. F., \& Maisyarah, M. (2021). Promosi Kesehatan dan Perilaku Kesehatan. Yayasan Kita Menulis.

Permatasari, D., \& Suprayitno, E. (2020). Implementasi Kegiatan Pendidik Sebaya dan Konselor Sebaya dalam Upaya Pencegahan Triad KRR di Pusat Informasi dan Konseling Remaja. Jurnal Ners Dan Kebidanan (Journal of Ners and Midwifery), 7(1), 143-150.

Permatasari, D., \& Suprayitno, E. (2021a). Factors Affecting The Role Of Peer 
Counselors In Implementing Adolescent Reproductive Health Education In Sumenep District. International Journal Of Nursing And Midwifery Science (IJNMS), 5(1), 16-23.

Permatasari, D., \& Suprayitno, E. (2021b). Pendampingan Remaja Putri Tentang Kesehatan Reproduksi Dalam Mengurangi Tingkat Stres Pada Saat Keputihan Di Pesantren Almuqri Parenduan. Jurnal Pengabdian Masyarakat Nusantara (JPMN), 1(1), 31-35.

Suprayitno, E., Purnomo, J. D. T., Sutikno, S., \& Indriyani, R. (2020). Health education in principle of community affected teenagaer's smooking attitude and habitual in the coastal area of madura island indonesia. International Journal of Psychosocial Rehabilitation, 24(10). https://doi.org/10.37200/IJPR/V24I10/PR300173

Suprayitno, Emdat, \& Huzaimah, N. (2020). Pendampingan lansia dalam pencegahan komplikasi hipertensi. SELAPARANG Jurnal Pengabdian Masyarakat Berkemajuan, 4(1), 518-521.

Suprayitno, Emdat, Pratiwi, I. G. D., \& Yasin, Z. (2018). Gambaran Penyebab Terjadinya Pembengkakan Payudara Pada Ibu Menyusui Di Polindes Desa Meddelen Kecamatan Lenteng. Wiraraja Medika, 8(1), 13-18.

Suprayitno, Emdat, \& Wahid, A. (2019). Pendampingan Tentang Penyakit Hipertensi Dan Perawatan Keluarga Dengan Hipertensi. Seminar Nasional Hasil Pengabdian Kepada Masyarakat, 3(1), 104-106. 